
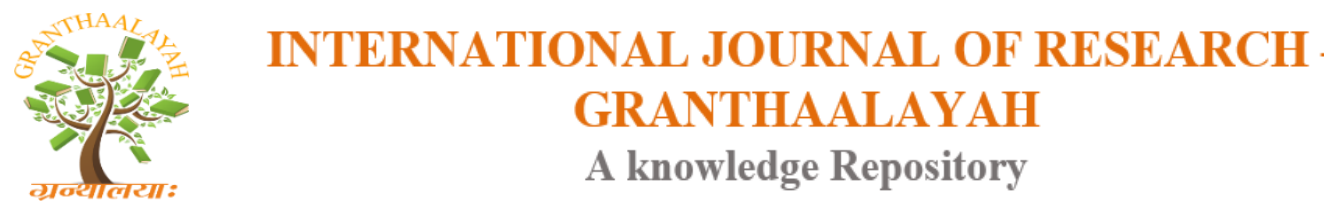

Science

\title{
ODONTOID FRACTURES
}

Sibhi Ganapathy ${ }^{1}$, Venkata Ramakrishna $T^{2}$, Swaroop Gopal ${ }^{3}$

${ }^{1,2,3}$ Institute of Neurosciences, Sakra World Hospital, Devarabeesanahalli, Banglore 560103, India

\begin{abstract}
Odontoid fractures account for approximately 7-15\% (1) of cervical spine fractures, and almost $60 \%$ of fractures involving the axis. Neurological involvement is seen in upto $25 \%$ pts (2), and the primary mortality rate is around $12 \%$ (2). The mean age of occurrence is 47 years, with 2 peaks. In younger individuals, the fracture usually occurs due to a high velocity injury. In the elderly, hyperextension of the head and neck during domestic falls is the most common mode of injury. These injuries are frequently missed in the elderly, and the mortality is higher as compared to younger patients.
\end{abstract}

Keywords: Odontoid; Fractures.

Cite This Article: Sibhi Ganapathy, Venkata Ramakrishna T, and Swaroop Gopal. (2018). "ODONTOID FRACTURES." International Journal of Research - Granthaalayah, 6(11), 409-426. https://doi.org/10.29121/granthaalayah.v6.i11.2018.1147.

\section{Introduction}

Odontoid fractures account for approximately $7-15 \%{ }^{(1)}$ of cervical spine fractures, and almost $60 \%$ of fractures involving the axis. Neurological involvement is seen in upto $25 \%$ pts ${ }^{(2)}$, and the primary mortality rate is around $12 \%{ }^{(2)}$. The mean age of occurrence is 47 years, with 2 peaks. In younger individuals, the fracture usually occurs due to a high velocity injury. In the elderly, hyperextension of the head and neck during domestic falls is the most common mode of injury. These injuries are frequently missed in the elderly, and the mortality is higher as compared to younger patients.

Type I \& type III fractures are successfully treated non-operatively, untreated type II fractures of the dens are known to have a $60 \%$ rate of non-union ${ }^{(1)}$.

\section{Applied Anatomy of the Odontoid}

The detailed anatomy of the craniovertebral junction (CVJ) has already been dealt with earlier in this monogram (chapter 2). Only the relevant surgical anatomy will be detailed in this chapter. 
The morphometry of the dens varies depending on the race and build of the person. The average length of dens ranges between $17-27 \mathrm{~mm}$. ${ }^{(3)}$ It has a posterior tilt of 14 degrees and a lateral tilt of 10 degrees. The average external transverse diameter of the dens is around $9.3 \mathrm{~mm}$ with an internal transverse diameter of $4.5 \mathrm{~mm}$. The mean antero-posterior external diameter is around $10.5 \mathrm{~mm}$. This implies that the permissible critical diameter for passage of screws into the odontoid, traversing the fractured segments is approximately $9 \mathrm{~mm} .{ }^{(4)}$

Nonunion is a cause of concern in odontoid fractures. The causes of non-union are thought to be:

1) The alar and apical ligaments attached to the apex of the odontoid hold the fractured dens away from the $\mathrm{C} 2$ body.

2) A vascular watershed exists between the apex and base of the odontoid. The apex is supplied by branches from the internal carotid, whilst the base is supplied from branches of the vertebral arteries. The fracture of the odontoid is believed to lie in this vascular watershed zone $^{(5)}$ (figure 1)

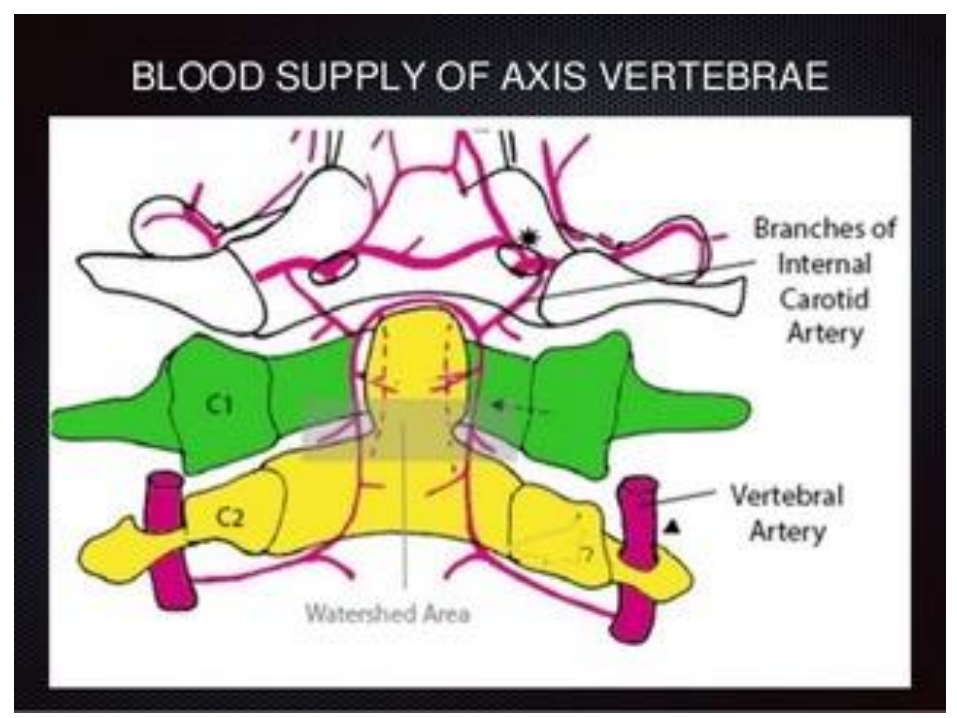

Figure 1: The blood supply of the odontoid

3) The odontoid is predominantly intra-synovial and the synovial fluid washes away the fracture hematoma.

\section{Anatomy of the Transverse Ligament}

The transverse ligament is the strongest and thickest ligament of the craniovertebral junction. Its function is to maintain the relation between the anterior arch of atlas and the odontoid. Failure of the transverse ligament allows anterior subluxation of $\mathrm{C} 1$ on $\mathrm{C} 2$. It extends between the tubercles on the medial side of the lateral mass of atlas, and passes behind the odontoid process in a shallow groove. It is concave in front and convex behind, and, broader and thicker in the middle. ${ }^{(6,7,8)}$ The average length of the transverse ligament is $21.9 \mathrm{~mm}$ with its thickness being $5-6 \mathrm{~mm}$. The transverse ligament has a mechanical strength of $350 \mathrm{~N}^{(9)}$ when subjected to a uniaxial load, beyond which it tears and causes C1-C2 instability. Transverse ligament tears are classified into 2 types depending on the site of injury ${ }^{(10)}$ (Table 1). 
Table 1: Dickman's classification of transverse ligament injury

\begin{tabular}{|l|l|}
\hline Type I & Intrasubstance tear \\
\hline Type II & $\begin{array}{l}\text { Bony avulsion of the tubercle on } \mathrm{C} 1 \text { lateral } \\
\text { mass. }\end{array}$ \\
\hline
\end{tabular}

Type 1 injuries are intrasubstance tear of the ligament either in the midsubstance or near its attatchment to the lateral masses of $\mathrm{C} 1$ (Figure 2a).

Type 2 injuries involve an isolated avulsion of the medial tubercle of the $\mathrm{C} 1$ lateral mass, or an avulsion with a fracture of the lateral mass (Figure 2b).

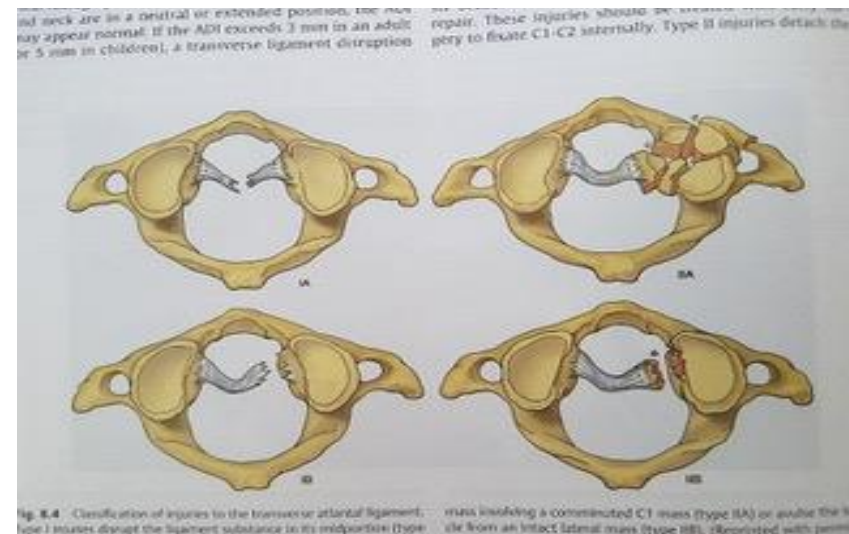

Figure 2: a- Intrasubstance tear of the transverse ligament, b- Avulsion of the transverse ligament from medial tubercle of $\mathrm{C} 1$ lateral mass

\section{Classification and Mechanism of Injury}

Anderson and D'Alonzo classified odontoid fractures into three types, based on the site of the fracture within the dens (Table 2 \& Figure 3):

Table 2: Anderson \& D'Alonzo`s classification. Haydley modification

\begin{tabular}{|l|c|}
\hline Type I & Avulsion facture at the tip of the odontoid (5.8\%) \\
\hline Type II & Simple fracture at the base of the odontoid $(67.5 \%)$ \\
\hline Type IIA & Comminuted fracture at the base of the odontoid \\
\hline Type III & Fracture through the C2 body (26.7\%) \\
\hline
\end{tabular}

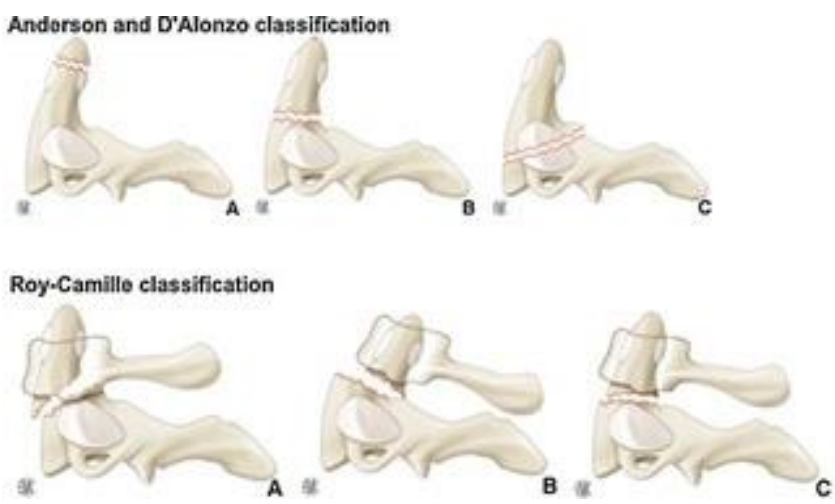

Figure 3: Anderson \& D`Alonzo Classification of odontoid fractures Type I Type II Type III 
The type I fracture constitutes $5.8 \%$ of all odontoid fractures ${ }^{(11)}$. It is usually an oblique avulsion of the tip of the dens by the alar ligament. It is postulated to occur when the head is in extension and a lateral shearing force is applied. This fracture occurs above the level of attachment of the transverse ligament and is usually stable. Rarely there may be associated atlanto-occipital dissociation, or an occipital condyle fracture. An os odontoideum is often misdiagnosed as an acute fracture. This can be differentiated on a CT scan, where the os odontoideum will have a cortical margin circumferentially.

The type II fracture is the most common dens fracture $(67.5 \%)^{(11)}$. It is a fracture of the waist of the odontoid, which occurs below the level of insertion of the transverse ligament. Hyperflexion injury when associated with transverse ligament rupture causes anterior displacement of the dens leading to its fracture. ${ }^{(12)}$ On the other hand, hyperextension causes direct impact of the anterior arch of atlas on the odontoid, resulting in a type II fracture with posterior displacement. ${ }^{(6)}$ The odontoid fracture in the pediatric population is at the synchondrosis and is more frequently associated with the neurological deficits due to the significant posterior displacement of the fractured fragment into the spinal canal. The neurological deficit is thought to be due to posterior displacement of the distal fragment and a consequent injury to the the spinal cord. ${ }^{(13,14)}$

Type II fractures are associated with no neurologic deficit in $82 \%$ patients, minimal sensory disturbance in $8 \%$ and significant deficits in $10 \%$. Later, Hadley ${ }^{(7,15)}$ described a comminuted variant of the type II fracture, which was classified as Type II A.

The type III fracture is a fracture through the body of $\mathrm{C} 2$ and may involve a variable portion of the $\mathrm{C} 1-\mathrm{C} 2$ joint. Because the fracture occurs within the cancellous bone of the vertebral body, usually there is an element of impaction, and very little displacement. There may be some angulation. It is essentially stable, not associated with a neurological deficit, and heals rapidly with immobilization. The mechanism of this injury is unclear, although axial loading is thought to be responsible.

Roy-Camille classified odontoid fractures based on the plane of the fracture and the direction of displacement of the dens ${ }^{(16)}$ (Table $3 \&$ figure 4)

Table 3: Roy- Camille classification of Odontoid fractures

\begin{tabular}{|l|l|}
\hline Type I & $\begin{array}{l}\text { Oblique linear fracture in which its line slopes forward, with dens displacement in an } \\
\text { anterior direction }\end{array}$ \\
\hline Type II & $\begin{array}{l}\text { Oblique linear fracture in which its line slopes backward, with dens displacement in a } \\
\text { posterior direction }\end{array}$ \\
\hline $\begin{array}{l}\text { Type } \\
\text { III }\end{array}$ & $\begin{array}{l}\text { Horizontal fracture line and the dens displacement can be } \\
\text { either anterior or posterior }\end{array}$ \\
\hline
\end{tabular}



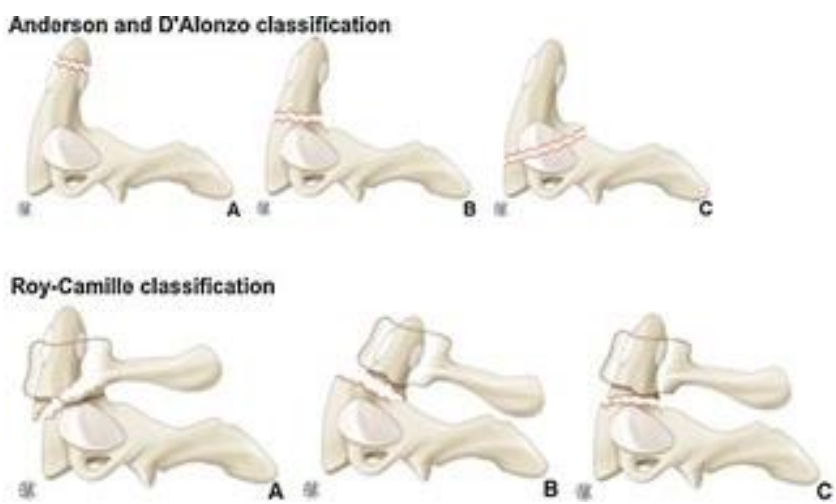

Figure 4: Roy Camille Classification of odontoid fractures Type I: Anterior oblique, Type II: Posterior oblique, Type III: Horizontal

\section{Diagnosis}

The diagnosis of odontoid fractures may sometimes be extremely challenging, especially in elderly patients, in children and in patients with multiple injuries. $17 \%$ of injuries to the CVJ are missed on plain films. Missed injuries may result in persistent pain and delayed neurologic deficits. Inadequate immobilization may also lead to non-union of the fracture.

In any patient with blunt trauma, complaining of neck pain, plain films- anteroposterior, lateral and open- mouth views are mandatory. Flexion- extension views are done for type I fractures, to rule out occipitocervical instability. Alternatively, thin section CT scans with sagittal and coronal reformations are performed. These have a 98\% sensitivity for diagnosis of an odontoid fracture. CT scans also help evaluate the fracture pattern, the degree of comminution, the direction of displacement and the age of the injury ${ }^{(17)}$. Associated injuries to the $\mathrm{C} 1$ arch or the sub-axial cervical spine can also be diagnosed. MRI scans may reveal injury to the transverse ligament, and also helps assess injury to the spinal cord.

The use of angiography routinely to diagnose vertebral artery injuries in these fractures is controversial. However, it is recommended that if the fracture line extends into the foramen transversorium, or if there is marked angulation or displacement of the odontoid fracture, then it is necessary to rule out a vertebral artery injury.

\section{Treatment}

There is no class I evidence in literature regarding the treatment protocol for the management of odontoid fractures. However, there is consensus ${ }^{(18)}$ that type 1 and type 3 fractures are successfully treated non-surgically over 6 to 12 weeks. Type 2 fractures can be treated either with immobilization or with surgery. Non-operative treatment is preferred when the fracture is undisplaced, and in those elderly patients who are poor risks for surgery. On the other hand, surgical intervention is preferred for displaced fractures, and in patients with symptomatic nonunions. 


\section{Non-Operative Treatment}

Type $1 \&$ Type III fractures ${ }^{(19)}$ are stable injuries that usually heal successfully with non-operative treatment. Stable Type I fractures are treated with a soft collar for comfort. Immobilization for type III fractures can be done with either a Philadelphia collar or a halo vest. Impacted type III can be treated with a Philadelphia collar. Undisplaced or minimally displaced type II fractures in young patients can also be similarly treated with halo-vest immobilization. A halo- vest exerts longitudinal distraction forces that help reduce the fracture. It limits $75 \%$ of cervical spine movements in flexion, extension, rotation and tilt, thereby effectively immobilizing the fracture. If the fracture reduction is lost, then the halo- vest can be adjusted to realign the spine. It permits early mobilization of the patient, thereby preventing complications that may arise out of maintaining a recumbent position for prolonged periods. Serial x-rays are taken to confirm the fracture reduction is maintained. At the end of 3 months, CT scans are repeated to look for fracture healing and alignment. Also flexion/ extension x-rays are done to look for evidence of instability. Fracture healing has been demonstrated in upto $85 \%$ of type II fractures, $97 \%$ of type III fractures and $67 \%$ of type II fractures associated with other injuries like a Jefferson fracture, when treated with halo- vest immobilization ${ }^{(20)}$.

However, patient acceptance of a halo-vest is a problem. The halo is painful at application, cumbersome to use for long periods, there may be pin site infection and bleeding from pins sites. Vests can be loosened by patients resulting in loss of reduction. Its prolonged usage may lead to cervical stiffness and there is an inability to maintain personal hygiene. Besides in elderly patients, halo-vests are reported to result in respiratory problems ${ }^{(21)}$. In fact, a significantly higher rate of complications and mortality has been reported in elderly patients with odontoid fractures treated with halo- vest immobilization. The current indications for halo- vest usage in odontoid fractures are enumerated in Table 4.

Table 4: Indications for halo- vest treatment in odontoid fractures

\begin{tabular}{|l|l|}
\hline & \multicolumn{1}{|c|}{ Type III fractures } \\
\hline 1. & Undisplaced Type II fractures \\
\hline 2. & Minimally displaced $(<3 \mathrm{~mm})$ type II fractures \\
\hline 3. & Type 2 transverse ligament injury \\
\hline 4. & Young patient \\
\hline
\end{tabular}

Hart et al reported on a series of elderly patients with chronic odontoid non-unions without myelopathy who were treated with a soft collar for comfort. None of these patients developed either myelopathy or progressive instability at follow-up. They believed that for elderly patients who are poor risks for surgery, this may be an option.

\section{Operative Treatment}

Patients in whom the odontoid peg is significantly displaced $(>3 \mathrm{~mm})$, severely angulated $\left(>10^{\circ}\right)$, comminuted fractures (Type II A), older patients (>40 years old), and those with transverse ligament injuries $(10 \%)$ have a greater chance of developing a non-union. Polytrauma victims who need to be mobilized early to prevent secondary complications, and elderly patients $(>65$ years old) who tolerate a halo-vest poorly may be candidates for early primary surgery. Patients with symptomatic, mobile non-union following an odontoid fracture must also be operated for pain 
relief and to prevent deformity and secondary neurologic deficit. Indications for surgery are listed in Table 5.

Table 5: Indications for surgery in Odontoid fractures

\begin{tabular}{|l|l|}
\hline 1. & Displaced $(>3 \mathrm{~mm})$ type II odontoid fractures \\
\hline 2. & Shallow type III fractures \\
\hline 3. & Severely angulated $\left(>10^{\circ}\right)$ \\
\hline 4. & Mid-substance tear of the transverse ligament \\
\hline 5. & Older patient $(>40$ years $)$ \\
\hline 6. & Polytrauma victims \\
\hline 7. & Non- union type II fractures \\
\hline
\end{tabular}

The goal of surgery in the treatment of acute odontoid fractures is to restore mechanical stability. This can be achieved in Type II odontoid fractures with one of the following techniques:

1) Anterior odontoid screw fixation

2) Posterior C1-C2 fusion

3) Transoral odontoidectomy and posterior fusion

\section{Anterior Odontoid Screw Fixation}

The desire to maintain motion at the atlanto-axial joint, reduction in need for additional bone grafts, and reduced need for a halo- vest immobilization, have made direct anterior fixation of the dens fracture a popular surgical option. Anterior screw fixation of the odontoid is recommended for Type II and shallow type III fractures in patients who have either failed conservative treatment, or are unable to tolerate halo- vests. However, prior to considering anterior screw fixation, one must ensure that the transverse ligament is intact, that the fracture is reducible and that the fracture line runs from posteroinferior to anterosuperior, i.e., perpendicular to the intended direction of the odontoid screw. The contra-indications for odontoid screw fixation are listed in Table 6

Table 6: Contra- indications to anterior odontoid screw fixation

\begin{tabular}{|l|l|}
\hline Absolute & Relative \\
\hline Transverse ligament injury & Barrel shaped chest, pendulous breasts \\
\hline C1- C2 instability & Short neck \\
\hline Significant comminution & Facial trauma making open mouth view difficult \\
\hline Inability to reduce the fracture & Osteoporosis \\
\hline Established non-union & Fracture line from posterosuperior to anteroinferior \\
\hline Pathological fracture & Associated Jefferson fracture \\
\hline
\end{tabular}

There has been considerable debate regarding the number of screws that need to be used to stabilize the odontoid fracture. Proponents of using two screws for stabilization pointed out that using two screws allowed greater rotational stability at the fracture site and higher fusion rates. Heller pointed out that some patients have small odontoids, so that the working diameter is $<9 \mathrm{~mm}$, which is the minimum diameter required for safely inserting two screws into the odontoid ${ }^{(22)}$. Sasso et al reported that the stability attained at the fracture site was the same, with both one and two screw constructs. Jenkins published that the fusion rates and clinical outcomes were similar between the one and two screw groups ${ }^{(22)}$. So a majority of surgeons simply use a single screw $(3.5-4 \mathrm{~mm}$ diameter) to stabilize the odontoid. 


\section{Anaesthesia}

Odontoid fractures are often unstable in both flexion and extension. Hence minimum movement of the neck is allowed during intubation, positioning, and reduction of the fracture in order to prevent spinal cord injury. Awake fiberoptic intubation is preferred so as to limit transmitting extension movement to the neck. Oral intubation is used. The endotracheal tube should be placed in such a way that it will not hinder the clear view of the odontoid on the fluoroscopic images. In case the odontoid fracture is accompanied by a cord injury, an adequate circulatory volume and blood pressure should be maintained. It is a routine practice in our institution to use intra-operative neuromonitoring in all unstable cervical fractures.

\section{Positioning and Reduction}

Initially the patient is placed in the supine position. For undisplaced or anteriorly displaced fractures, the reduction is achieved simply with positioning the neck in slight extension by keeping jelly rolls in the interscapular region. This position also allows the correct trajectory for proper screw insertion. In posteriorly displaced fractures, a few bedsheets may be kept below the head to provide the flexion for reduction of the fracture. Gentle cervical traction is applied using 6 to 10 pounds of weight over Gardener- Wells tongs (Figure 5).

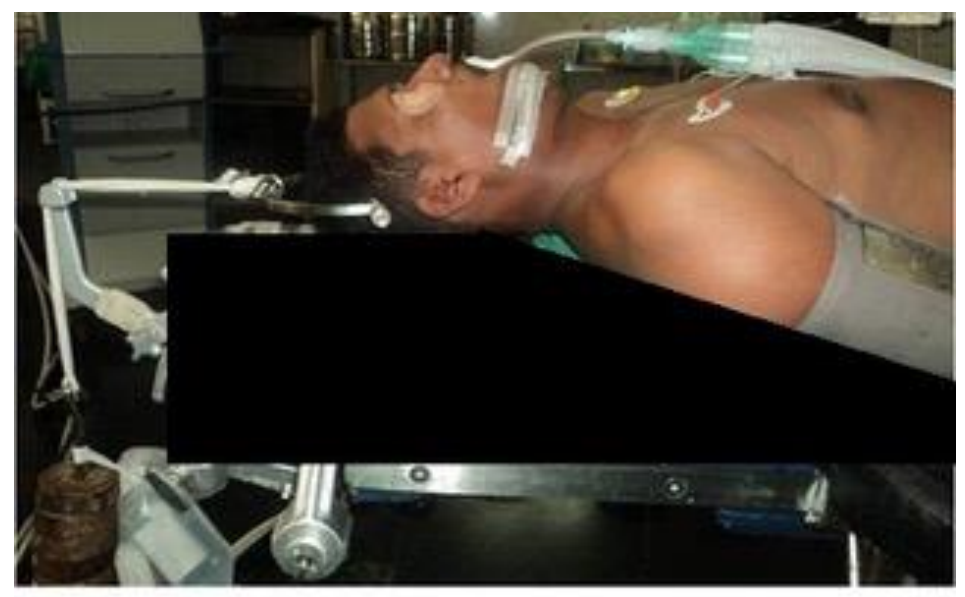

Figure 5: Positioning of the neck during anterior odontoid screw fixation

This helps to realign the fracture fragments, as well as to stabilize the head during the procedure. Adequate reduction of the fracture is mandatory for performing anterior odontoid screw fixation. Reduction must be ensured before starting the surgery. If it cannot be achieved, then the procedure is abandoned, and preparations are made for a posterior atlantoaxial fusion.

For patients in whom the fracture is not reducible by simple positioning, one of the following methods may be used to obtain reduction of the fracture.

\section{Progressive traction}

Traction can be applied using increasing weights in order to obtain a reduction (Figure 6). Reduction is assessed using cross-table lateral fluoroscopy while the patient is being maintained on traction. Close monitoring of vital parameters and neurological condition is essential in such patients. Lewellen et al., have documented respiratory arrest in four patients while they were being maintained on a traction for the treatment of posteriorly displaced fractures. ${ }^{(23)}$ 

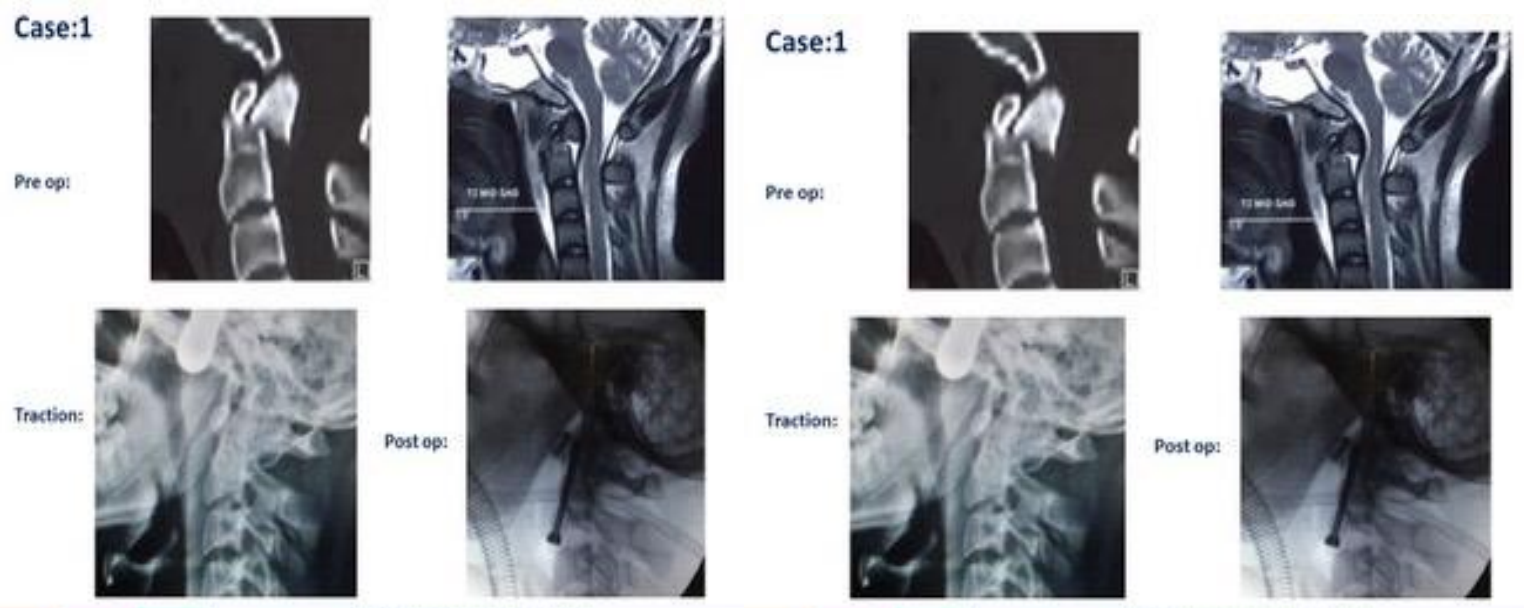

Figure 6: 45yM, polytrauma victim- posteriorly displaced Type II fracture reduced with positioning and $4 \mathrm{kgs}$ traction. Fixed with anterior odontoid screw

\section{Transoral Pressure on Posterior Pharyngeal Wall}

Reduction of the anteriorly displaced fracture fragment can be achieved by applying posteriorly directed pressure on the posterior pharyngeal wall through the trans-oral route. This pressure can be applied by the anaesthetist with sponges using a sponge holder (figure 7).

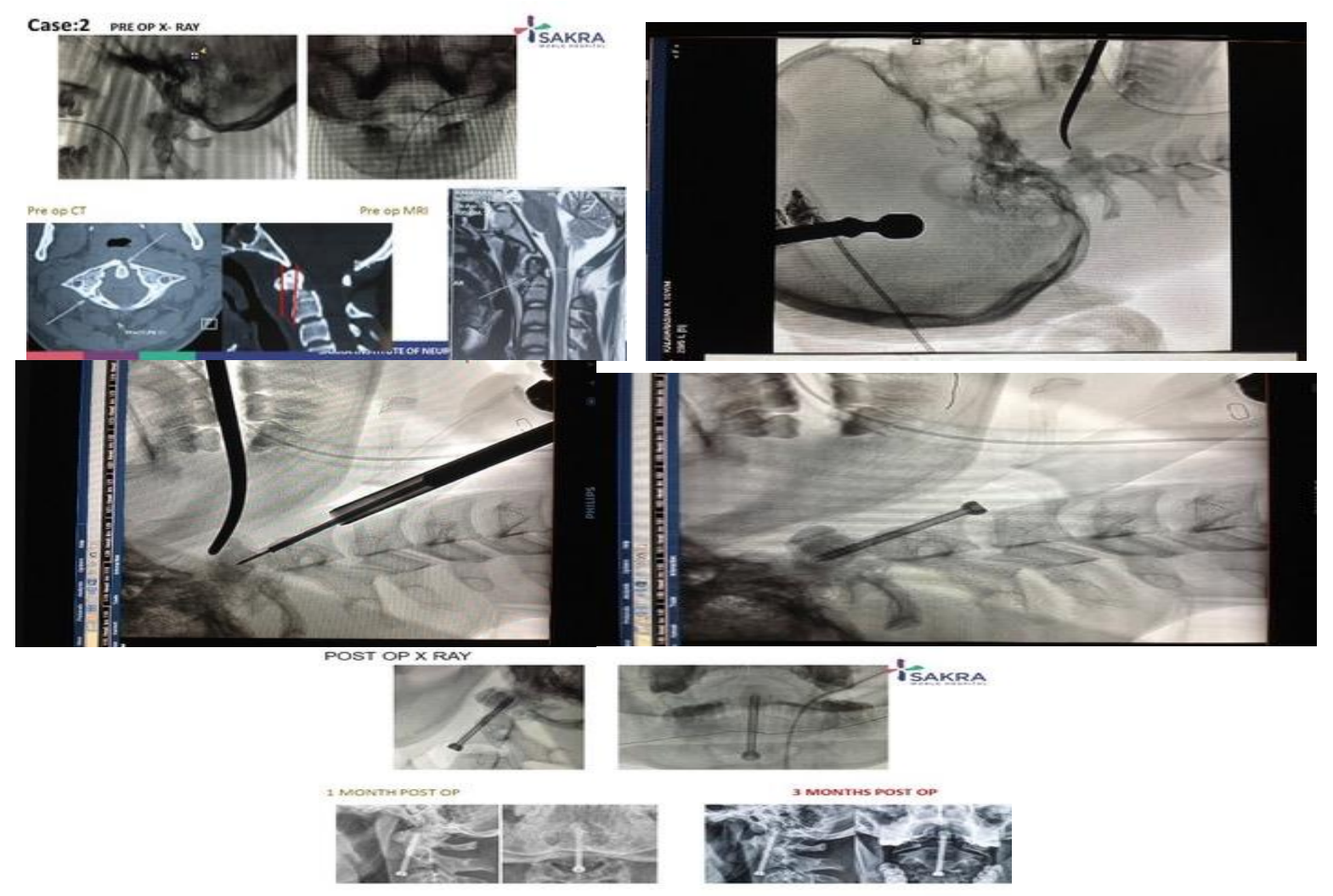

Figure 7: Type II anteriorly displaced fracture odontoid with C1 arch fracture. Reduced intraoperatively with pressure on posterior pharyngeal wall and fixed with anterior odontoid screw 
Radiolucent tamps are also available for this purpose. Trial reduction is done before the surgery. Intra-operatively when the Kwire and subsequently the screw are being inserted, the same reduction manoeuvre must be repeated. The reduction is confirmed by the lateral $\mathrm{C}$ arm images. Once the reduction is satisfactory, anterior odontoid screw fixation is performed. ${ }^{(24)}$

\section{Transoral Approach and Fracture Reduction}

Occasionally, the odontoid fracture fragment is inverted or hitched against the $\mathrm{C} 1 \mathrm{arch}$. This is usually seen in cases where an intact apical ligament is pulling the fragment superiorly, as depicted in figure 8 .

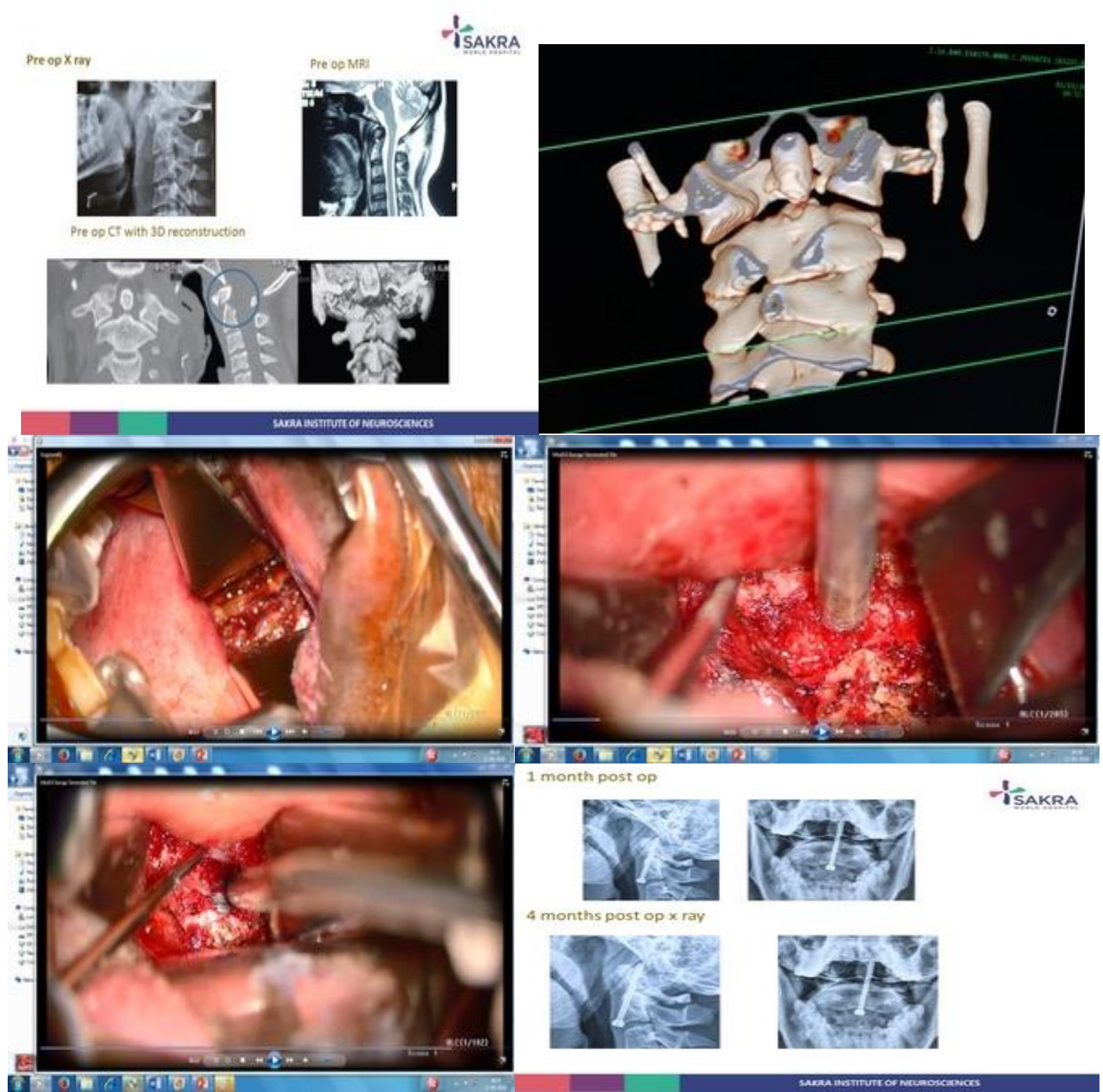

Figure 8: A- Type II odontoid fracture with proximal fragment displaced anteriorly and flipped . B \& C Transoral reduction of the fracture. D- Intra-operative CT scan showing reduction of the fracture. E- Transoral view showing threads of the screw at the fracture site. F- Xray at 4 month follow-up 
Here a transoral, transphrayngeal approach can be taken to visulaize the fracture and reduce the fracture fragments prior to screw insertion via the retropharyngeal route.

\section{Intra- Operative Imaging}

For odontoid screw fixation, biplanar fluoroscopy is mandatory. This can be achieved with the simultaneous use of two $\mathrm{C}$-arms, or by using a single machine but moving it back and forth for the open mouth and lateral views. The fluoroscopy machines are placed as depicted in figure 9.

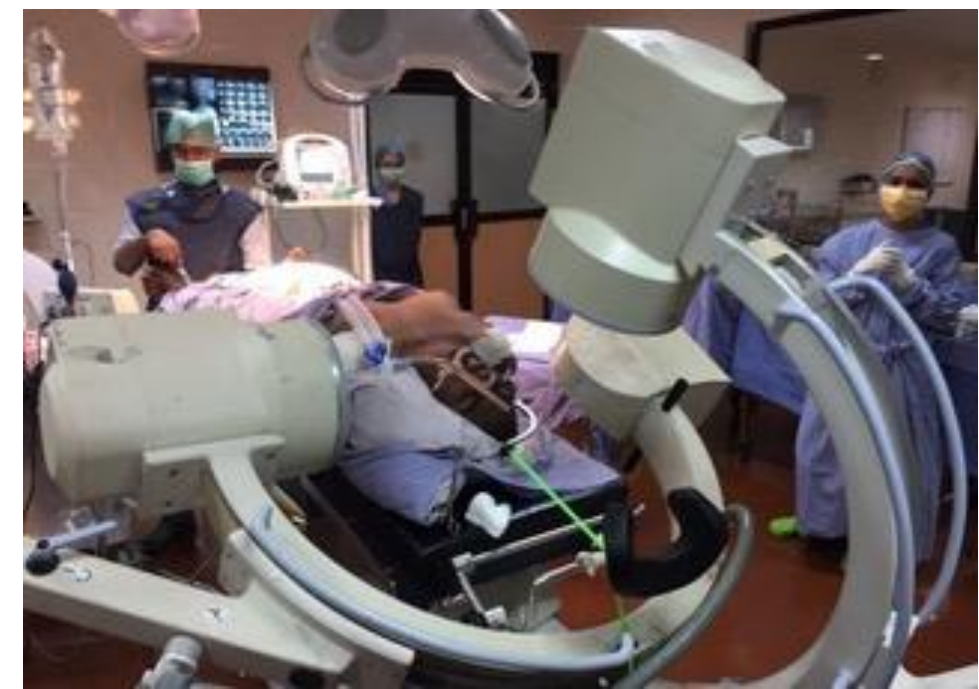

Figure 9: Positioning of the two Carms during anterior odontoid screw fixation

It is important to have a clear visibility of the odontoid fragment as well as the C1-2 joints in the anteroposterior view, which can be achieved by using open mouth x-rays. To get a clear image, a radiolucent mouth gag or the cork of a wine bottle could be used. Some surgeons simply pack a bundle of gauze pieces into the mouth, to keep it open. On lateral view, both the C2 and C3 vertebrae must be clearly seen. Fluoroscopic images should be obtained at the eye level of the surgeon. Use of neuronavigation, an $\mathrm{O}$ arm or an intra-operative computed tomographic scan will help to confirm the reduction and proper alignment of the fractured fragment before the surgeon proceeds to place the odontoid screw.

\section{Operative Technique}

The incision is placed at the C5-6 level using the transverse natural skin crease incision. The platysma layer superiorly is undermined to get a good access to the C2-3disc space. A standard anterior retropharyngeal approach is used to develop a plane between the carotid sheath on one side, and trachea-oesophagus plane on the other. The pre-vertebral region is exposed. The blunt dissection is carried cranially till the exposure of the C2-3-disc space. In some patients, the anterior surface of the $\mathrm{C} 3$ body may be projecting anteriorly; or, there may be the presence of anterior osteophytes. Partial shaving needs to be done to get an easy access as well as to obtain a proper trajectory for the placement of the drill at the anterior edge of the end plate of the $\mathrm{C} 2$ vertebrae. Using monopolar cautery, the longus colli muscles on both the sides are undermined at C2-disc place level to properly position the retractor blades. It would be useful to have radiolucent retractor blades. This low trajectory is needed for the proper anterior odontoid screw placement. 
Using the universal cannulated system under fluoroscopic guidance, an entry site is created in the midline on the anteroinferior edge of the $\mathrm{C} 2$ vertebra using an awl, for placing a single odontoid screw. The entry site has to be $3-4 \mathrm{~mm}$ from the midline for the two screw insertion technique. Care and patience in selecting the entry site and in setting the guide wire will be rewarded by the remainder of the procedure being expedited. Once the entry point is confirmed on the biplanar fluoroscopic image, a pilot hole is drilled using a cannulated drill bit exactly in the midline along the selected trajectory for 3 to $4 \mathrm{~mm}$. The drill bit is disconnected from the drill, and is left there. The guide wire is then passed through the drill and slowly advanced across the fracture site. The goal should be for the guide wire to engage the centre of the dense cortical shell at the apex of the proximal fragment, both on AP and lateral projections. Occasionally, a more dorsal trajectory is needed where a greater care needs to be undertaken to prevent the penetration of the screw into the spinal canal or cause a breach of the anterior cortical margin of the $\mathrm{C} 2$ body. The guide wire is then left there and the cannulated drill bit is passed over the K-wire to create a pilot hole. Care must be taken not to push the initial K-wire further inside when drilling. Also when withdrawing the drill, the K- wire frequently gets jammed in the drill bit and comes out with the drill bit if one is not careful. The screw length will be measured on the $\mathrm{K}$-wire after removing the drill and a cannulated lag screw of $3.5 \mathrm{~mm}$ diameter and appropriate length is inserted to oppose the fracture ends. The screw head should snuggly fit at the ventral edge of the $\mathrm{C} 2$ vertebrae and not resting on the C3 upper endplate. The wound is cleaned and platysma layer is closed with 5-0 absorbable sutures and the wound closed with subcutaneous and subcuticular sutures.

Post-operatively, the patient is mobilized the same evening with a soft collar for comfort, and can be discharged the same day. Literature shows a 93-95\% fusion rate with this direct method of screw fixation in odontoid fractures ${ }^{(25)}$. Percutaneous/endoscopic anterior odontoid screw fixation techniques have now been described in order to further minimize soft-tissue trauma.

\section{Complications}

Anterior odontoid screw fixation is an extremely demanding operation. The indications are very precise, and the surgical technique is extremely demanding. In 1989, Aebi reported a $24 \%$ complication rate, that included malreduction (19\%), pseudoarthrosis (12\%), malposition of screws $(2 \%)$ and screw breakage $(1.5 \%)^{(26)}$. In 1999, Andersson et al reported that anterior screw fixation had either failed or healed after a complicated post-operative course in 8 out of 11 elderly patients (mean age 78 years). They postulated that the stiff neck in the elderly, precluded adequate positioning for reduction and for proper screw trajectory. Also weak, osteoporotic bone did not offer sufficient purchase for the stable screw fixation. In 2001, Arand reported on 58 patients with type II \& shallow type III fractures, fixed with either one or two screws. 14 patients (24\%) developed a significant complication, of which 10 patients required revision surgery. Besides this they reported malreduction in 14 patients $(24 \%)$, and lateral cortical perforation by a screw in 10 patients $(17 \%)^{(27)}$. Complications included rupture of the carotid artery while winding around the motor drill, complete malplacement of the screw behind the odontoid process and oesophageal perforation resulting in deep wound infection.

Since these early days, the indications for anterior screw fixation have been refined, and the instrumentation for screw insertion has improved significantly. More recent studies have shown significantly lesser complication rates and excellent outcomes even in the elderly age group. Some 
authors have even suggested cement augmentation of the anterior odontoid screw in the elderly, osteoporotic patient ${ }^{(28)}$.

The complications of anterior screw fixation of the odonotoid are listed in table 7 (figure 10).

Table 7: Complications of anterior odontoid screw fixation

\begin{tabular}{|l|l|l|}
\hline Intra-operative & Early post-operative & Delayed post-operative \\
\hline Malreduction & Malposition of screw & Non-union \\
\hline Misplaced screw & Displacement of fracture & Screw breakage \\
\hline Long screw & Haematoma & Screw migration \\
\hline $\begin{array}{l}\text { Injury to spinal cord due to k- } \\
\text { wire/ screw }\end{array}$ & Dysphagia & Malunion \\
\hline Breakage of K-wire & Neurologic deficit & \\
\hline & Infection & \\
\hline
\end{tabular}

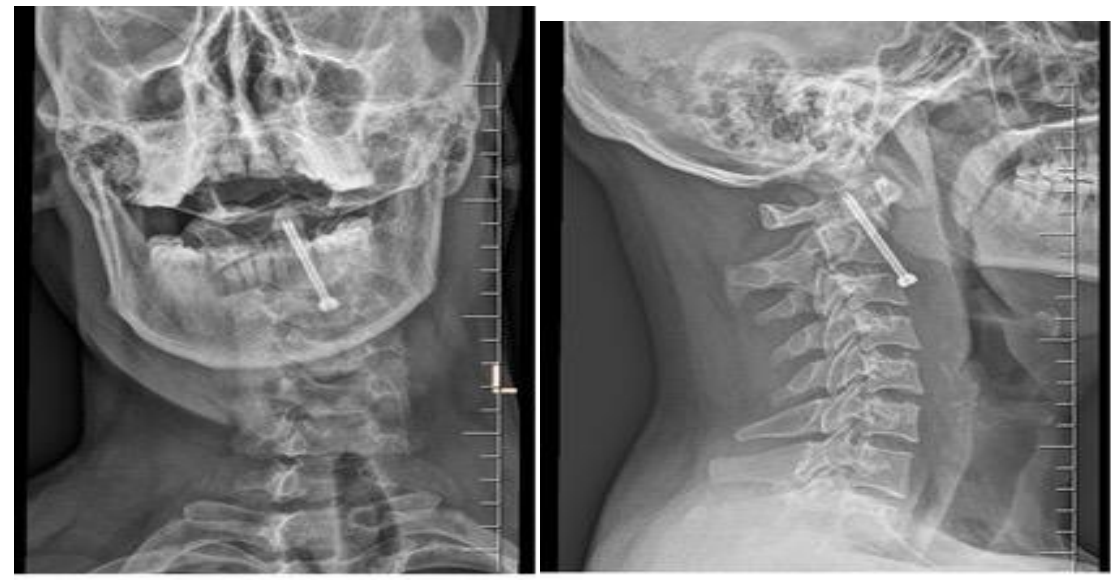

Figure 10: Misplaced odontoid screws with displaced odontoid

\section{Posterior C1-C2 Fusion}

Posterior atlantoaxial fusion is generally not the preferred surgical option for treating fresh odontoid fractures, because it results in significant restriction of neck movements. Posterior C1C2 fusion is advised for patients who do not tolerate halo- vest immobilization, in those whom anterior screw fixation is contra-indicated (table 8),

Table 8: Anterior odontoid screw fixation: Pearls \& pitfalls

\begin{tabular}{|c|c|c|}
\hline & $\begin{array}{r}\text { Pearls } \\
\end{array}$ & Pitfalls \\
\hline Anaesthesia & $\begin{array}{l}\text { - Awake fibreoptic } \\
\text { endotracheal intubation } \\
\text { - Manual in- line stabilization } \\
\text { of neck during intubation }\end{array}$ & $\begin{array}{l}\text { - Nasal intubation will hinder } \\
\text { open mouth view } \\
\text { - Neck movements can cause SCI }\end{array}$ \\
\hline Positioning & $\begin{array}{l}\text { - At edge of table towards the } \\
\text { surgeon } \\
\text { - Extension for anteriorly } \\
\text { displaced \# \& flexion for } \\
\text { posteriorly displaced \# }\end{array}$ & $\begin{array}{l}\text { - If adequate extension not given, } \\
\text { difficult to get right trajectory } \\
\text { for screw insertion } \\
\text { - In patients with short necks, } \\
\text { pendulous breasts, barrel shaped }\end{array}$ \\
\hline
\end{tabular}




\begin{tabular}{|c|c|c|}
\hline & $\begin{array}{l}\text { - Gentle traction for stabilizing } \\
\text { the neck }\end{array}$ & $\begin{array}{l}\text { chest- difficult to get right } \\
\text { trajectory for screw insertion }\end{array}$ \\
\hline Fluoroscopy & $\begin{array}{l}\text { For open mouth AP view, tilt } \\
\text { the c-arm cephalad } \\
\text { - Gauze pieces/ wine bottle } \\
\text { cork used to keep mouth open } \\
\text { for AP xray }\end{array}$ & $\begin{array}{l}\text { - In patients with facial fractures, } \\
\text { mouth opening may be } \\
\text { restricted precluding an } \\
\text { adequate open mouth view } \\
\text { If the odontoid peg \& the C1- } \\
\text { C2 joints are not seen clearly, } \\
\text { screw malposition chances are } \\
\text { high }\end{array}$ \\
\hline Reduction & $\begin{array}{l}\text { Positioning in extension for } \\
\text { ant displaced \#, and in flexion } \\
\text { for post displaced \# } \\
\text { - Gentle traction helps align the } \\
\text { fracture fragments. Traction } \\
\text { must be released before final } \\
\text { tightening of screw } \\
\text { Pressure on posterior } \\
\text { pharyngeal wall helps } \\
\text { reduction }\end{array}$ & $\begin{array}{l}\text { If adequate reduction is not } \\
\text { achieved, then anterior screw } \\
\text { fixation may have to be } \\
\text { abandoned } \\
\text { - Reduction can be lost during } \\
\text { surgical manoeuvres } \\
\text { - If reduction is obtained by } \\
\text { posterior pharyngeal pressure, } \\
\text { the pressure must be maintained } \\
\text { during entire procedure or else } \\
\text { the screw tract gets lost }\end{array}$ \\
\hline Access & $\begin{array}{l}\text { A guide wire is placed on the } \\
\text { neck in the approximate } \\
\text { direction of the screw on } \\
\text { lateral view. This guides } \\
\text { incision } \\
\text { - Undermining platysma helps } \\
\text { access to C } 2 / 3 \text { disc } \\
\text { Radiolucent retractors if } \\
\text { available are helpful }\end{array}$ & $\begin{array}{l}\text { Carotid artery and oesophagus } \\
\text { can get entangled in the wire } \\
\text { and drill } \\
\text { - Excessive medial retraction can } \\
\text { result in post-op dysphagia }\end{array}$ \\
\hline $\begin{array}{l}\text { Screw starting } \\
\text { point }\end{array}$ & $\begin{array}{l}\text { Midline on AP view aiming at } \\
\text { the centre of the tip of the } \\
\text { odontoid } \\
\text { - Shave off the anterior surface } \\
\text { of C3 with a drill- starting } \\
\text { point is located at the } \\
\text { anteroinferior corner of C2, } \\
\text { almost within C2-3 disc } \\
\text { - Small movements of the hand } \\
\text { while selecting entry point } \\
\text { and direction, effect large } \\
\text { changes in direction on the c- } \\
\text { arm view }\end{array}$ & $\begin{array}{l}\text { - More anterior/ superior entry } \\
\text { point pushes the guide wire into } \\
\text { a more posterior trajectory } \\
\text { More inferior/ posterior } \\
\text { endpoint with a vertical drilling } \\
\text { trajectory can result in anterior } \\
\text { cortical breach }\end{array}$ \\
\hline
\end{tabular}




\begin{tabular}{|c|c|c|}
\hline $\begin{array}{l}\text { K-Wire } \\
\text { insertion }\end{array}$ & $\begin{array}{l}\text { Initially start with the drill bit } \\
\text { for } 2 \text { to } 3 \mathrm{~mm} \text {, to get a hold in } \\
\text { the bone. Then insert the } \\
\text { guide wire through the drill } \\
\text { - Aim for the middle of the tip } \\
\text { of the peg in both planes } \\
\text { The guide wire should have a } \\
\text { hold in the cortical bone at the } \\
\text { apex of the odontoid }\end{array}$ & $\begin{array}{l}\text { Guide wire can be pushed } \\
\text { forward during the drilling } \\
\text { process } \\
\text { Guide wire can be pulled out } \\
\text { when removing drill/ tap }\end{array}$ \\
\hline Screw insertion & $\begin{array}{l}\text { Screw length must be precise } \\
\text { to allow purchase in the apical } \\
\text { cortical bone so as to achieve } \\
\text { compression at fracture site } \\
\text { - Screw threads must not cross } \\
\text { the fracture site to allow } \\
\text { compression } \\
\text { - Screw should be sitting flush } \\
\text { on the anteroinferior border of } \\
\text { odontoid }\end{array}$ & $\begin{array}{l}\text { - A fracture line traversing from } \\
\text { anteroinferior to posterosuperior } \\
\text { may not be amenable to screw } \\
\text { fixation } \\
\text { - Guide wire can be pushed in } \\
\text { during screw insertion } \\
\text { - Reduction may be lost } \\
\text { - If screw direction is not precise, } \\
\text { it can displace the fracture } \\
\text { - Long screw can penetrate the } \\
\text { apex of the dens injuring the } \\
\text { cord } \\
\text { - If fracture gap is not closed after } \\
\text { seating of screw, chances of } \\
\text { non-union are high }\end{array}$ \\
\hline
\end{tabular}

and in those patients where previous anterior surgery has failed. Various types of posterior atlantoaxial fixation options are available including wiring techniques, Halifax clamps, transarticular C1- C2 screw fixation and C1 lateral mass with $\mathrm{C} 2$ pedicle/ pars/ translaminar screws stabilization are described in detail in other chapters of the monogram.

\section{Transoral Odontoidectomy with Posterior C1- C2 Fusion}

Odontoidectomy is done for cases of malunited odontoid fractures where the malunited odontoid compresses the thecal sac compromising the canal and the patients present with neurological deficits (figure 11). This is a rare situation. Odontoidectomy in these circumstances is usually performed along with a posterior C1-2 fusion under the same anaesthesia.

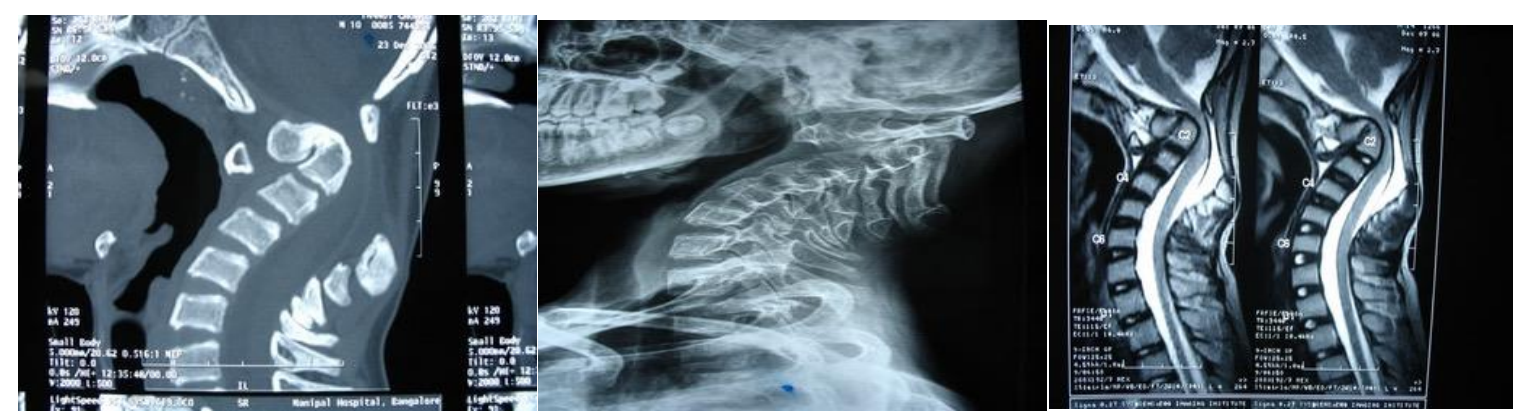

Figure 11: Malunited dens fracture with spinal cord compression- Needs treatment with a transoral odontoidectomy 


\section{Conclusions}

Odontoid fractures are the most common fractures of axis and are caused due to both flexion and extension injuries. Type I and type III fractures heal well and are usually treated non-operatively. Fracture healing has been reported in upto $85 \%$ of undisplaced or minimally displaced Type II fractures in young patients, who can tolerate halo- vest immobilization. Elderly patients (>70 years) who incur more than $20 \%$ of odontoid fractures, do not tolerate the halo-vest, and hence are candidates for surgical stabilization.

The primary options for surgical treatment are anterior odontoid screw fixation and posterior atlantoaxial fusion. Anterior odontoid screw preserves the $\mathrm{C} 1-\mathrm{C} 2$ rotation, and hence should be the procedure of first choice, especially in young patients provided they have an intact transverse atlantal ligament (TAL). Fragment reduction is mandatory prior to the anterior odontoid screw fixation, and hence, aggressive reduction manoeuvers are undertaken to reduce the fracture before the surgical intervention. In cases of transverse ligament injury, a C1-C2 posterior fusion is recommended. Odontoid fractures, if neglected, may lead to delayed neurological deficits.

\section{Key Learning Points}

- $17 \%$ of injuries to the craniovertebral junction are missed on plain Xrays- especially in the elderly, in children \& in polytrauma victims

- An odontoid fracture is the most common upper cervical injury. It is frequently associated with head injury, other $\mathrm{C} 1 / \mathrm{C} 2$ injuries, subaxial cervical spine fractures. These must be proactively looked for and excluded

- Type I fracture is mostly stable and can be treated with a soft collar. It can be confused with an os odontoideum

- Type III fractures are through the cancellous part of the C2 body and involve the C1/ C2 joint variably. They are treated non-operatively successfully

- Untreated or inadequately immobilized type II fractures have a non-union rate of $5 \%$ to $60 \%$ in literature. Non-union can result in atlantoaxial instability, deformity and neurologic deficit.

- Elderly patients (>70 years) tolerate halo- vest immobilization poorly. Type IIA comminuted fractures are common and the bone is osteoporotic. Posterior C1- C2 fusion is the surgery of choice. If anterior odontoid fixation is performed, augmentation with bone cement may be an option.

- Approximately $85 \%$ of type II fractures in younger patients heal with halo- vest immobilization. Surgery is indicated in displaced fractures, polytrauma victims and in those that do not tolerate halo- vests.

- Anterior odontoid screw fixation is the preferred option for surgically treating type II fractures. Pre-requisites for this procedure are an intact transverse ligament, ability to reduce the fracture intra-operatively and a fracture line conducive to screw passage

\section{References}

[1] Ryan MD, Taylor TK. Odontoid fractures. A rational approach to treatment. Bone \& Joint Journal. 1982 Aug 1;64(4):416-21. 
[2] Patel A, Smith HE, Radcliff K, Yadlapalli N, Vaccaro AR. Odontoid fractures with neurologic deficit have higher mortality and morbidity. Clinical Orthopaedics and Related Research ${ }^{\circledR} .2012$ Jun 1;470(6):1614-20.

[3] Khaleel ZL, Besachio DA, Bisson EF, Shah LM. Estimation of odontoid process posterior inclination, odontoid height, and $\mathrm{pB}-\mathrm{C} 2$ line in the adult population: Clinical article. Journal of Neurosurgery: Spine. 2014 Feb;20(2):172-7.

[4] Heller JG, Amrani J, Hutton WC. Transverse ligament failure: a biomechanical study. Clinical Spine Surgery. 1993 Apr 1;6(2):162

[5] Sakaida H, Waga S, Kojima T, Kubo Y, Niwa S, Matsubara T. Os odontoideum associated with hypertrophic ossiculum terminale: case report. Journal of Neurosurgery: Spine. 2001 Jan;94(1):140-4.

[6] Doherty BJ, Heggeness MH, Esses SI. A biomechanical study of odontoid fractures and fracture fixation. Spine. 1993; 18:178-184.

[7] Hadley MN, Browner CM, Liu SS, Sonntag VK. New subtype of acute odontoid fractures (type IIA). Neurosurgery. 1988 Jan 1;22(1):67-71.

[8] Vassiou K, Eftichia K, Marinos K, Kotrogianni F, Fanariotis M, Fezoulidis I, Arvanitis D. Magnetic resonance imaging of the ligaments of the craniocervical region at 3Tesla magnetic resonance unit: Quantitative and qualitative assessment.

[9] Dvorak J, Schneider E, Saldinger P, Rahn B. Biomechanics of the craniocervical region: the alar and transverse ligaments. Journal of Orthopaedic Research. 1988 May 1;6(3):452-61.

[10] Dickman CA, Greene KA, Sonntag VK. Injuries involving the transverse atlantal ligament: classification and treatment guidelines based upon experience with 39 injuries. Neurosurgery. 1996 Jan 1;38(1):44-50.

[11] Anderson LD, D'Alonzo RT. Fractures of the odontoid process of the axis. J Bone Joint Surg Am. 1974; 56:1663-74.

[12] Mouradian WH, Fietti VG, Chochran GVB, Fielding JW, Young J. Fractures of the odontoid: a laboratory and clinical study of mechanism. Orthop Clin North Am. 1978; 9:985-1001.

[13] Blauth M, Otte D, Krettek C. Fractures of the odontoid process in small children: biomechanical analysis and report of three cases. European Spine Journal. 1996 Feb 21;5(1):63-70.

[14] Odent T, Langlais J, Glorion C, Kassis B, Bataille J, Pouliquen JC. Fractures of the odontoid process: a report of 15 cases in children younger than 6 years. Journal of Pediatric Orthopaedics. 1999 Jan 1;19(1):51-4.

[15] 15. Adam D, Cergan R, Iftimie D, Moisescu C. Odontoid fracture that is not listed in the existing classifications A new subtype of odontoid fracture: case report. Romanian Neurosurgery. 2016 Mar 1;30(1):57-64.

[16] Roy-Camille R, Saillant G, Judet T et-al. Factors of severity in the fractures of the odontoid process (author's transl). Rev Chir Orthop Reparatrice Appar Mot. 1981;66 (3): 183-6. Pubmed citation.

[17] Jain N, Verma R, Garga UC, Baruah BP, Jain SK, Bhaskar SN. CT and MR imaging of odontoid abnormalities: A pictorial review. The Indian journal of radiology \& imaging. 2016 Jan;26(1):108.

[18] Julien TD, Frankel B, Traynelis VC, Ryken TC. Evidence- based analysis of odontoid fracture management. Neurosurg Focus 2000; 8: 1-6.

[19] Polin RS, Szabo T, Bogaev CA, Replogle RE, Jane JA. Nonoperative management of Types II and III odontoid fractures: the Philadelphia collar versus the halo vest. Neurosurgery. 1996 Mar $1 ; 38(3): 450-7$.

[20] Vieweg U, Schultheiss R. A review of halo vest treatment of upper cervical spine injuries. Archives of orthopaedic and trauma surgery. 2001 Jan 1;121(1-2):50-5.

[21] White AP, Hashimoto R, Norvell DC, Vaccaro AR. Morbidity and mortality related to odontoid fracture surgery in the elderly population. Spine. 2010 Apr 20;35(9S): S146-57.

[22] Jenkins JD, Coric D, Branch Jr CL. A clinical comparison of one-and two-screw odontoid fixation. Journal of neurosurgery. $1998 \mathrm{Sep} ; 89(3): 366-70$. 
[23] Przybylski GJ, Harrop JS, Vaccaro AR. Closed management of displaced type II odontoid fractures: more frequent respiratory compromise with posteriorly displaced fractures. Neurosurgical focus. 2000 Jun;8(6):1-3.

[24] Tamer Orief, Khaled Almusrea,Ibrahim Assiri,Department of Spine Surgery, National Neurosciences Institute, King Fahad Medical City, Riyadh, Saudi Arabia Direct transoral reduction of anteriorly displaced type II odontoidfracture during anterior odontoid screw fixation: Review of literatureInternational Journal of Spine Surgery 6 (2012) 206-209.

[25] Scheyerer MJ, Zimmermann SM, Simmen HP, Wanner GA, Werner CM. Treatment modality in type II odontoid fractures defines the outcome in elderly patients. BMC surgery. 2013 Nov 9;13(1):54.

[26] Aebi M, Etter C, Coscia M. Fractures of the Odontoid Process Treatment with Anterior Screw Fixation. Spine. 1989 Oct 1;14(10):1065-70.

[27] Feng G. Biomechanical Comparison of Anterior Screw Fixation Techniques for Type II Odontoid Fractures: One-Versus Two-Screw Fixation (Doctoral dissertation, University of Lübeck).

[28] Kohlhof H, Seidel U, Hoppe S, Keel MJ, Benneker LM. Cement-augmented anterior screw fixation of Type II odontoid fractures in elderly patients with osteoporosis. The Spine Journal. 2013 Dec 1;13(12):1858-63.

\footnotetext{
*Corresponding author.
}

E-mail address: sibhig@yahoo.co.uk. 